\title{
Systolic time interval as index of schedule-dependent doxorubicin cardiotoxicity in patients with acute myelogenous leukaemia
}

\author{
S A D AL-ISMAIL, J A WHITTAKER
}

British Medical fournal, 1979, 1, 1392-1395

\section{Summary and conclusions}

The ratio of the pre-ejection period to the left ventricular ejection time (PEP:LVET) was measured in two groups of patients with acute myeloblastic leukaemia (AML) receiving the anthracycline antibiotic doxorubicin (DXR). Patients receiving high doses of DXR per course (about $90 \mathrm{mg} / \mathrm{m}^{2}$ ) showed a significant increase in the PEP:LVET ratio irrespective of the total cumulative dose. At a lower dose per course (less than $50 \mathrm{mg} / \mathrm{m}^{2}$ ) only patients who had a total cumulative dose of over $450 \mathrm{mg} / \mathrm{m}^{2}$ showed significant increases in ratio. ECG changes were seen in both groups of patients but did not correlate significantly with the dosage. These findings, which suggest that DXR cardiotoxicity is schedule dependent, are important in the design of schedules of DXR for treating cancer and in interpreting the changes in systolic time intervals (STIs) observed with different schedules.

Measurement of the STI is a simple and convenient method of assessing DXR cardiotoxicity. While a total DXR dose of $550 \mathrm{mg} / \mathrm{m}^{2}$ should not normally be exceeded, by carefully monitoring the STI the recommended total dose may be exceeded safely in selected patients.

\section{Introduction}

The most effective treatments for acute myeloblastic leukaemia (AML) in adults are those that include the anthracycline antibiotics daunorubicin or doxorubicin (DXR). ${ }^{1}$ DXR is also extremely effective in the management of many solid tumours. ${ }^{2}$ s Bone-marrow depression is the major short-term toxic effect, others include nausea and vomiting, stomatitis, alopecia, and phlebitis at the injection site. DXR cardiotoxicity, which is related to the total cumulative dose, constitutes the major limiting factor when this valuable chemotherapeutic agent is used. ${ }^{1-5}$

The clinical and laboratory features of DXR cardiomyopathy are those of congestive heart failure, the most striking characteristic being the rapidly progressive course. ${ }^{6}$ The condition may be controlled if diagnosed early and treated intensively, but monitoring the ECG, chest $x$-ray films, and cardiac enzyme concentrations is not helpful in predicting DXR cardiotoxicity. ${ }^{4{ }^{78}}$ Minow et al, ${ }^{9}$ however, showed that a low QRS voltage was present at the onset of congestive heart failure, and they suggested that a reduction of $40 \%$ or more in the total absolute deflection of the QRS complex measured on the six limb leads when associated with any clinically detectable cardiac abnormality may be an indication to discontinue DXR treatment.

Rinehart et $a^{8}$ reported that measuring the systolic time

Department of Haematology, Welsh National School of Medicine and University Hospital of Wales, Cardiff CF4 4XW

$S$ A D AL-ISMAIL, MB, MRCP, senior registrar

J A WHITTAKER, MD, MRCP, senior lecturer and consultant haematologist interval (STI) and particularly the ratio of the pre-injection period (PEP) to left ventricular ejection time (LVET) aided early detection of DXR cardiotoxicity. Eight of their nine patients who had a total cumulative dose of DXR ranging from 310 to $540 \mathrm{mg} / \mathrm{m}^{2}$ showed significantly increased ratios, while only one out of nine patients who had a lower total cumulative dose did so. They concluded that the STI was the most sensitive indicator for predicting DXR cardiotoxicity. These results were not confirmed by Minow et $\mathrm{al}^{\circ}$, who observed only one case of cardiac toxicity in 54 patients treated with doses exceeding 450 $\mathrm{mg} / \mathrm{m}^{2}$. Weiss and Manthe $\mathrm{l}^{10}$ suggested that DXR cardiotoxicity in man may be schedule dependent as well as related to the total cumulative dose. This might partly explain the discrepancy found by different workers in the value of the STI and other indices in predicting DXR cardiomyopathy, as different dosage schedules may have been used.

We have attempted to evaluate the STI and other measurements in predicting DXR cardiotoxicity and have carefully examined the effect of different dosage schedules on these indices.

\section{Patients and methods}

We studied 23 adults with a diagnosis of $A M L$, who were divided into two groups. Group 1 comprised patients receiving about $90 \mathrm{mg} / \mathrm{m}^{2}$ of DXR in each treatment course (range 88-94 $\mathrm{mg} / \mathrm{m}^{2}$ ) as part of their induction treatment together with cytarabine (cytosine arabinoside) and thioguanine. The patients had different total cumulative doses of DXR, ranging from 90 to $758 \mathrm{mg} / \mathrm{m}^{2}$ (table I). Treatment courses were repeated every three to four weeks. Group 2 comprised patients receiving smaller doses of DXR in each treatment course (less than $50 \mathrm{mg} / \mathrm{m}^{2}$ ), either as part of other forms of reinduction treatment or as maintenance chemotherapy. The total cumulative dose ranged from 80 to $675 \mathrm{mg} / \mathrm{m}^{2}$ (table II). These patients were also receiving cytarabine with or without thioguanine. There was no significant difference in the total cumulative dose between the two groups. We also studied a control group of 10 patients, four with acute leukaemia, who were receiving chemotherapeutic agents other than anthracyclines (table III). No patient in any of the groups had radiotherapy to the mediastinum or precordium. The patients' histories, clinical examination, ECG, and chest radiograph showed no evidence of cardiovascular disease. STIs were measured using a multichannel photographic system by simultaneously recording the ECG, phonocardiogram, and carotid pulse tracing. ${ }^{11}$ The PEP:LVET ratio and changes in PEP, LVET, and total electromechanical systole corrected for heart rate $^{12-14}$ were used to evaluate left ventricular function. A chest $x$-ray film and standard 12-lead ECG were obtained for each patient at the time of measurement. These measurements were carried out before and three weeks after each course of treatment. If patients showed any appreciable change in the STI the measurements were repeated at two-weekly intervals.

\section{Results}

GROUP 1

Twelve of the 15 patients showed a significant $(>0.08)$ increase in the PEP:LVET ratio, the mean for the whole group being 0.14 (table I). This increase, however, occurred irrespective of whether the total cumulative dose was low or high. The ratio returned to normal in four to 10 weeks' time except in two patients, in whom it 
continued to increase. Ultimately these two patients developed evidence of congestive heart failure, which was treated successfully in both. One patient has been described in full previously ${ }^{15}$ and the history in the other case is described below.

Case report-A 44-year-old woman presented in December 1975 with a history of lethargy, loss of weight, and spontaneous bruising of a few days' duration. A diagnosis of AML was established by bonemarrow examination. Induction chemotherapy consisted of courses of daunorubicin, $1.5 \mathrm{mg} / \mathrm{kg}$, and cytarabine, $1 \mathrm{mg} / \mathrm{kg} 12$-hourly intravenously for five days. She entered a full haematological remission after five courses: The remission was maintained with cytarabine and daunorubicin (later DXR). When the total cumulative dose of the anthracycline antibiotics reached $594 \mathrm{mg} / \mathrm{m}^{2}$ further maintenance chemotherapy was with cytarabine and thioguanine. There were no clinical, electrocardiographic, or radiographic changes suggestive of cardiac dysfunction. Maintenance chemotherapy was stopped after two years of uninterrupted complete remission, but after only a few months she relapsed again. Reinduction treatment was with cytarabine given intravenously for seven days and DXR, $90 \mathrm{mg} / \mathrm{m}^{2}$ divided over 72 hours on days 5,6 , and 7 . Her ECG, chest $x$-ray films, and STIs were monitored. The PEP:LVET ratio, ECG, and chest $x$-ray films were normal before the reinduction chemotherapy was begun. Two weeks after the last injection of DXR she developed shortness of breath and the PEP:LVET ratio increased progressively to a value of

TABLE I-Details of patients receiving high doses of doxorubicin per course (about $90 \mathrm{mg} / \mathrm{m}^{2}$ ), showing changes in cardiac function

\begin{tabular}{|c|c|c|c|c|c|c|c|c|c|}
\hline \multirow{2}{*}{$\begin{array}{l}\text { Observation } \\
\text { No }\end{array}$} & \multirow{2}{*}{ Sex } & \multirow{2}{*}{$\begin{array}{c}\text { Age } \\
\text { (years) }\end{array}$} & \multirow{2}{*}{$\begin{array}{l}\text { Total dose } \\
\left(\mathrm{mg} / \mathrm{m}^{2}\right)\end{array}$} & \multicolumn{6}{|c|}{ Change in: } \\
\hline & & & & Heart rate & $\mathrm{QS}_{2} \mathrm{I}$ & LVETI & PEPI & PEP:LVET & $\operatorname{ECG}(\%) *$ \\
\hline $\begin{array}{r}1 \\
2 \\
3 \\
4 \\
5 \\
6 \\
7 \\
8 \\
9 \\
10 \\
11 \\
12 \\
13 \\
14 \\
15\end{array}$ & $\begin{array}{l}M \\
\mathrm{~F} \\
\mathrm{M} \\
\mathrm{M} \\
\mathrm{F} \\
\mathrm{F} \\
\mathrm{M} \\
\mathrm{M} \\
\mathrm{M} \\
\mathrm{M} \\
\mathrm{M} \\
\mathrm{F} \\
\mathrm{M} \\
\mathrm{F} \\
\mathrm{F}\end{array}$ & $\begin{array}{l}29 \\
47 \\
25 \\
43 \\
35 \\
23 \\
37 \\
17 \\
55 \\
70 \\
51 \\
30 \\
31 \\
16 \\
46\end{array}$ & $\begin{array}{r}176 \\
180 \\
240 \\
180 \\
176 \\
270 \\
270 \\
90 \\
180 \\
176 \\
94 \\
90 \\
758 \\
623 \\
688\end{array}$ & $\begin{array}{l}-10 \\
+3 \\
+21 \\
+4 \\
-15 \\
+29 \\
+48 \\
+38 \\
-4 \\
+36 \\
+18 \\
+24 \\
+24 \\
+19 \\
+10\end{array}$ & $\begin{array}{l}+5 \\
-10 \\
+29 \\
+32 \\
-34 \\
+34 \\
+18 \\
+36 \\
+3 \\
+13 \\
-4 \\
-0 \cdot 5 \\
+35 \\
+2 \\
+43\end{array}$ & $\begin{array}{l}-10 \\
-19 \\
-33 \\
+5 \\
-50 \\
+1 \\
-34 \\
+7 \\
-34 \\
+6 \\
-35 \\
-0 \cdot 1 \\
-4 \\
-27 \\
+8\end{array}$ & $\begin{array}{l}+15 \\
+9 \\
+62 \\
+27 \\
+16 \\
+33 \\
+52 \\
+29 \\
+37 \\
+7 \\
+31 \\
-0 \cdot 4 \\
+39 \\
+29 \\
+35\end{array}$ & $\begin{array}{l}+0.06 \\
+0.12 \\
+0.2 \\
+0.09 \\
+0.13 \\
+0.15 \\
+0.14 \\
+0.14 \\
+0.17 \\
+0.07 \\
+0.22 \\
+0.05 \\
+0.23 \\
+0.17 \\
+0.13\end{array}$ & $\begin{array}{r}-15 \\
-4 \\
-30 \\
+26 \\
-11 \\
-19 \\
-14 \\
0 \\
-10 \\
0 \\
0 \\
-12 \\
-4 \\
-3 \\
-50\end{array}$ \\
\hline Mean & & 37 & 279 & 16 & 13 & -15 & +28 & $+0 \cdot 138$ & -10 \\
\hline
\end{tabular}

$\mathrm{QS}_{2} \mathrm{I}=$ Total electromechanical systolic index (that is, corrected for heart rate).

LVETI = Left ventricular ejection time index.

PEPI $=$ Pre-ejection period index.
Percentage change in absolute deflection of QRS complex.

TABLE II-Details of patients receiving doxorubicin in doses of under $50 \mathrm{mg} / \mathrm{m}^{2}$ per course, showing changes in cardiac function

\begin{tabular}{|c|c|c|c|c|c|c|c|c|c|c|}
\hline \multirow{2}{*}{$\begin{array}{l}\text { Observation } \\
\text { No }\end{array}$} & \multirow{2}{*}{ Sex } & \multirow{2}{*}{$\underset{\text { (years) }}{\text { Age }}$} & \multirow{2}{*}{$\begin{array}{c}\text { Dose per } \\
\text { course }\left(\mathrm{mg} / \mathrm{m}^{2}\right)\end{array}$} & \multirow{2}{*}{$\begin{array}{l}\text { Total cumulative } \\
\text { dose }\left(\mathrm{mg} / \mathrm{m}^{2}\right)\end{array}$} & \multicolumn{6}{|c|}{ Change in: } \\
\hline & & & & & Heart rate & $\mathrm{QS}_{2} \mathrm{I}$ & LVETI & PEPI & PEP:LVET & $\operatorname{ECG}(\%)^{*}$ \\
\hline $\begin{array}{l}16 \\
17 \\
18 \\
19 \\
20 \\
21 \\
22 \\
23 \\
24 \\
25 \\
26 \\
27\end{array}$ & $\begin{array}{l}M \\
F \\
M \\
M \\
F \\
M \\
F \\
F \\
F \\
M \\
F \\
M\end{array}$ & $\begin{array}{l}30 \\
68 \\
55 \\
35 \\
19 \\
71 \\
60 \\
64 \\
34 \\
29 \\
23 \\
25\end{array}$ & $\begin{array}{l}47 \\
39 \\
39 \\
38 \\
40 \\
40 \\
42 \\
40 \\
35 \\
34 \\
39 \\
37\end{array}$ & $\begin{array}{r}675 \\
526 \\
466 \\
489 \\
330 \\
80 \\
84 \\
160 \\
247 \\
205 \\
348 \\
310\end{array}$ & $\begin{array}{l}+40 \\
-29 \\
+13 \\
+15 \\
+8 \\
+23 \\
+2 \\
-3 \\
+35 \\
-8 \\
+10 \\
-35\end{array}$ & $\begin{array}{l}+35 \\
-29 \\
-1 \\
-11 \\
+12 \\
+22 \\
+14 \\
+25 \\
+15 \\
+7 \\
+9 \\
-9\end{array}$ & $\begin{array}{l}+11 \\
-56 \\
-9 \\
-25 \\
+6 \\
+24 \\
+8 \\
+33 \cdot 3 \\
-5 \\
+17 \\
+6 \\
+6\end{array}$ & $\begin{array}{l}+24 \\
+27 \\
+8 \\
+14 \\
+6 \\
-2 \\
+6 \\
-7 \cdot 8 \\
+20 \\
-10 \\
+3 \\
-15\end{array}$ & $\begin{array}{l}+0.15 \\
+0.18 \\
+0.11 \\
+0.12 \\
+0.02 \\
-0.01 \\
+0.01 \\
-0.07 \\
+0.12 \\
-0.07 \\
+0.01 \\
+0.05\end{array}$ & $\begin{array}{r}-34 \\
+18 \\
-18 \\
0 \\
-13 \\
0 \\
0 \\
-1 \\
-11 \\
-15 \\
-19 \\
-38\end{array}$ \\
\hline Mean & & 43 & 39 & 326 & +5.9 & +7 & 1 & 6 & 0.05 & -10 \\
\hline
\end{tabular}

$\mathrm{QS}_{2} \mathrm{I}=$ Total electromechanical systolic index (that is, corrected for heart rate)

LVETI = Left ventricular ejection time index.

*Percentage change in absolute deflection of QRS complex.

TABLE III-Details of control group of 10 patients receiving chemotherapeutic agents other than doxorubicin

\begin{tabular}{|c|c|c|c|c|c|c|c|c|c|}
\hline \multirow{2}{*}{$\begin{array}{l}\text { Observation } \\
\text { No }\end{array}$} & \multirow[b]{2}{*}{ Sex } & \multirow[b]{2}{*}{ Age } & \multirow[b]{2}{*}{ Diagnosis } & \multirow[b]{2}{*}{ Drugs received } & \multicolumn{5}{|c|}{ Change in: } \\
\hline & & & & & Heart rate & $\mathrm{QS}_{2} \mathrm{I}$ & LVETI & PEPI & PEP:LVET \\
\hline $\begin{array}{l}28 \\
29\end{array}$ & $\begin{array}{l}M \\
M\end{array}$ & $\begin{array}{l}29 \\
16\end{array}$ & $\begin{array}{l}\text { Hodgkin's disease } \\
\text { Acute lymphoblastic } \\
\text { leukaemia }\end{array}$ & $\begin{array}{l}\text { MOPP } \\
\text { Cytarabine, } \\
\text { methotrexate }\end{array}$ & $\begin{array}{l}-1 \\
+22\end{array}$ & $\begin{array}{l}+6 \\
+20\end{array}$ & $\begin{array}{l}+3 \\
+11\end{array}$ & $\begin{array}{l}+3 \\
+9\end{array}$ & $\begin{array}{l}+0.01 \\
+0.03\end{array}$ \\
\hline $\begin{array}{l}30 \\
31\end{array}$ & $\stackrel{M}{\mathrm{~F}}$ & $\begin{array}{l}63 \\
70\end{array}$ & $\begin{array}{l}\text { Hodgkin's disease } \\
\text { Acute myeloblastic } \\
\text { leukaemia }\end{array}$ & $\begin{array}{l}\text { MOPP } \\
\text { Cytarabine, } \\
\text { thioguanine }\end{array}$ & $\begin{array}{c}-18 \\
0\end{array}$ & $\begin{array}{l}+17 \\
-32\end{array}$ & $\begin{array}{l}+18 \\
-4\end{array}$ & $\begin{array}{l}-1 \\
-28\end{array}$ & $\begin{array}{l}-0.05 \\
-0.01\end{array}$ \\
\hline 32 & F & 25 & $\begin{array}{l}\text { Acute lymphoblastic } \\
\text { leukaemia }\end{array}$ & Cytarabine & +1 & +20 & +4 & +16 & +0.05 \\
\hline 33 & $\mathbf{M}$ & 22 & $\begin{array}{l}\text { Acute lymphoblastic } \\
\text { leukaemia }\end{array}$ & $\begin{array}{l}\text { Cytarabine, } \\
\text { mercaptopurine }\end{array}$ & +9 & +5 & +18 & -13 & -0.05 \\
\hline $\begin{array}{l}34 \\
35 \\
36 \\
37\end{array}$ & $\begin{array}{l}F \\
M \\
M \\
F\end{array}$ & $\begin{array}{l}19 \\
29 \\
23 \\
37\end{array}$ & $\begin{array}{l}\text { Hodgkin's disease } \\
\text { Hodgkin's disease } \\
\text { Lymphoma } \\
\text { Lymphoma }\end{array}$ & $\begin{array}{l}\text { MOPP + bleomycin } \\
\text { MOPP + bleomycin } \\
\text { Cyclophosphamide } \\
\text { Cyclophosphamide, } \\
\text { vincristine, prednisone }\end{array}$ & $\begin{array}{l}-13 \\
-1 \\
+17 \\
+8\end{array}$ & $\begin{array}{l}-2 \\
+8 \\
+12\end{array}$ & $\begin{array}{l}+1 \\
-2 \\
+11 \\
-3\end{array}$ & $\begin{array}{l}-3 \\
+2 \\
-3 \\
+15\end{array}$ & $\begin{array}{l}-0.02 \\
+0.1 \\
-0.02 \\
-0.05\end{array}$ \\
\hline Mean & & 33 & & & +2 & +5 & +6 & -0.3 & -0.001 \\
\hline
\end{tabular}

$\mathrm{QS}_{2} \mathrm{I}=$ Total electromechanical systolic index (that is, corrected for heart rate).

LVETI = Left ventricular ejection time index.

PEPI $=$ Pre-ejection period index.

MOPP = Mustine, vincristine (Oncovin), prednisone, and procarbazine 
0.63 , indicating severe left ventricular dysfunction. The total amplitude of the QRS complex decreased by $50 \%$ and a chest $x$-ray film showed cardiac enlargement. She was treated with digoxin and diuretics, and her general condition and exercise tolerance were soon remarkably improved. The heart size returned to normal on the chest $x$-ray film but her ECG and STI remained abnormal. She entered a second haematological remission, in which she continued.

\section{GROUP 2}

Eight patients were already in remission and four others entered remission, and it was possible to continue their DXR as part of their maintenance chemotherapy. The mean change in ratio for the whole group was +0.05 (table II). All four patients who had a total cumulative dose of over $450 \mathrm{mg} / \mathrm{m}^{2}$ showed a significant increase in the ratio (figure). The ratio increased in one of the eight patients

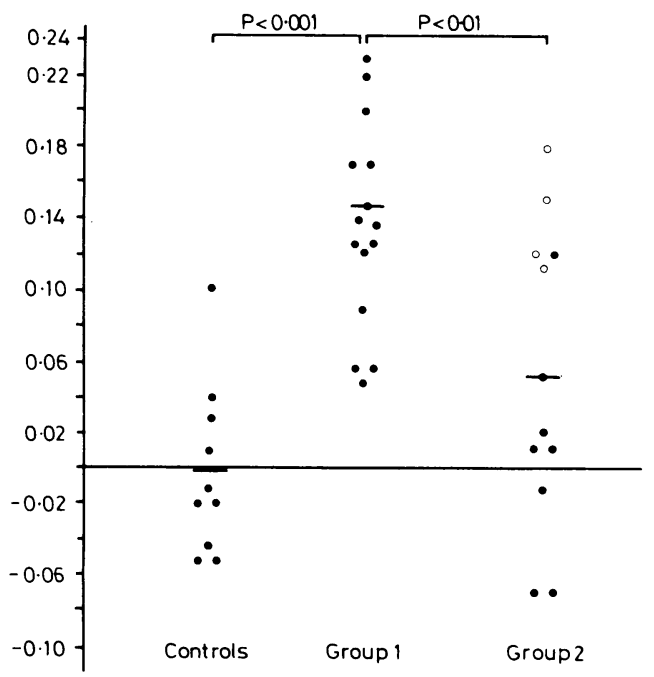

Changes in PEP:LVET ratio in controls and both groups of patients. Horizontal bars indicate mean change in each group.

$\mathrm{O}=$ Patients with cumulative doses of over $450 \mathrm{mg} / \mathrm{m}^{2}$.

who had a total cumulative dose of less than $450 \mathrm{mg} / \mathrm{m}^{2}$. Subsequent measurements of the ratio in this patient remained abnormal, and therefore further DXR was withheld and she was maintained on cytarabine and thioguanine. The only other evidence of myocardial dysfunction in this patient was shortness of breath on mild to moderate exertion. Chest radiography did not disclose any cardiac enlargement and ECG changes were not present.

When groups 1 and 2 were compared patients in group 1 showed higher increase in the PEP:LVET ratio (fig). Only one patient in the control group showed a significant increase in the ratio.

\section{CHANGES IN THE ECG}

The most common ECG changes observed in our patients were abnormalities in cardiac rhythm, particularly supraventricular and ventricular arrhythmias and non-specific ST-segment and T-wave abnormalities. These changes, however, were not specific, as they occurred at all cumulative doses, were unrelated to the dosage schedule, and did not necessarily recur after further injections of DXR. Most of the changes, particularly the ventricular and supraventricular premature beats, disappeared within a few hours.

Measurements of the absolute deflections of the QRS complex in the six limb leads as suggested by Minow et al were also carried out. In group 1 only the patient whose case report is presented above showed a decrease in the amplitude of more than $50 \%$, the mean decrease for the group being $10 \%$. These changes did not correlate significantly with the total cumulative dose of DXR. In group 2 two patients showed $34 \%$ and $38 \%$ decreases in QRS amplitude. The mean decrease for the whole group was $10 \%$. Similarly, these changes showed no significant correlation with the total dose of DXR.

\section{Discussion}

One-third of patients receiving DXR at a total dosage of more than $550 \mathrm{mg} / \mathrm{m}^{2}$ are estimated to develop cardiotoxicity, ${ }^{5}$ and it has become customary not to exceed this dosage because of the possibility of developing clinical cardiomyopathy. Consequently patients with malignant disease and a poor prognosis have not been eligible to receive further DXR, even though two-thirds of these patients may not have developed cardiotoxicity at dosages exceeding $550 \mathrm{mg} / \mathrm{m}^{2}$. On the other hand, a few patients may develop cardiotoxicity at a lower cumulative dose than the recommended $550 \mathrm{mg} / \mathrm{m}^{2} .{ }^{6} 81617$ These observations emphasise the importance of tests that might help to predict DXR cardiotoxicity and permit more accurate dose limitation. In our view it is equally important that these tests should be non-invasive and that the physician should have easy access to them. Methods like endomyocardial biopsy may be sensitive in detecting the myocardial injury produced by $\mathrm{DXR}^{1819}$ but their use is limited to research purposes and they are not suitable for patients with severe thrombocytopenia. Echocardiograms may also be sensitive indicators of impending or asymptomatic cardiomyopathy. Significant variation of the ejection fractions were seen in six of the 13 patients treated with DXR at a dose exceeding $400 \mathrm{mg} / \mathrm{m}^{2}$, two of whom had clinical signs of congestive heart failure. ${ }^{20} \mathrm{~A}$ decrease in fractional shortening may be an even more sensitive echocardiographic measurement. ${ }^{21}$

The method of measuring the STI is simple and available in almost all hospitals. Controversy exists, however, about the value of this non-invasive test in assessing DXR cardiotoxicity, possibly because the toxicity may, apart from being related to the total cumulative dose, be partly schedule dependent and thus changes in the STI and other indices must be analysed with this in mind.

Our results show that in patients receiving courses of treatment containing a high dose of DXR (group 1) the changes in the PEP:LVET ratio did not correlate with the total cumulative dose, since patients who had a small total dose also showed changes, albeit transient ones. These transient changes in STI, however, are not in any way comparable with the non-specific ECG changes that are observed at all cumulative doses irrespective of dosage schedule. ${ }^{5}{ }^{922}$ The increase in the PEP:LVET ratio was repeatedly observed in our patients receiving induction courses of $90 \mathrm{mg} / \mathrm{m}^{2}$. Patients in group 2 who received a smaller dose per course (less than $50 \mathrm{mg} / \mathrm{m}^{2}$ ) did not show these changes while their total cumulative dose was below $450 \mathrm{mg} / \mathrm{m}^{2}$. It seems, then, that a high dose of DXR per course results in myocardial injury irrespective of the total cumulative dose, and in patients who have already had a high total dose, the values take longer to return to normal. This suggests that DXR cardiotoxicity is at least partly schedule dependent. Arena et al suggested that the uptake of DXR by myocardial cells may be schedule dependent. ${ }^{23}$ Weiss and Manthel $^{10}$ found that they could exceed a total dose of $600 \mathrm{mg} / \mathrm{m}^{2}$ with only slight risk of severe cardiomyopathy developing by giving DXR weekly instead of three weekly. They suggested that DXR cardiotoxicity may be in some way related to the peak concentrations of the drug in the body and that accumulation of DXR by the myocardial cell is schedule dependent.

In our patients the ratio returned to normal or near-normal values in two to 10 weeks except in two cases. In both patients cardiotoxicity was observed after widely separated courses of DXR. Measurements of the STI were helpful in predicting the cardiotoxicity, and both patients were treated successfully with conventional antifailure measures. One showed a decrease of $50 \%$ in the absolute voltage of the QRS complex measured on the six limb leads as suggested by Minow et al, while the other showed a decrease in QRS voltage of less than $10 \%$.

The change in the STI in relation to the total cumulative dose was compared in patients receiving a dose of under $50 \mathrm{mg} / \mathrm{m}^{2}$ per course. All four patients who had a total cumulative dose of more than $450 \mathrm{mg} / \mathrm{m}^{2}$ showed a significant increase in the PEP:LVET ratio. DXR was stopped in these patients, who 
were then followed up. Seven of the eight patients who had a total cumulative dose of less than $450 \mathrm{mg} / \mathrm{m}^{2}$ did not show a significant change.

Measurement of the STI is a sensitive means of detecting myocardial injury induced by DXR. It should be emphasised that changes in the STI may subside weeks or months after stopping the drug, even in patients who may have a very high total dose. These patients, however, remain at high risk of developing congestive heart failure if DXR is restarted, even up to two years after the last dose of the drug. We recommend, therefore, that a total dose of DXR of $550 \mathrm{mg} / \mathrm{m}^{2}$ should not be exceeded unless the benefit of achieving further remission outweighs the risk of cardiotoxicity. Carefully monitoring cardiac function by measuring the STI in these circumstances will aid the early detection of myocardial dysfunction. Finally, as the recommended total dose of DXR is relatively low, the drug is probably best reserved for induction treatment in patients with AML. This is especially important if modern induction protocols using relatively high doses per course are used. Maintenance chemotherapy may be carried out using noncardiotoxic agents known to be effective in this disease.

\section{References}

${ }^{1}$ Freireich, E J, et al, Archives of Internal Medicine, 1976, 136, 1417.

${ }^{2}$ Blum, R H, and Carter, S, Annals of Internal Medicine, 1974, 80, 249.

${ }^{3}$ Pratt, C B; Shanks, E C, and Memphis, R N, American fournal of Diseases of Children, 1974, 127, 534.
4 Benjamin, R S, Wiernik, P H, and Bachur, N R, Cancer, 1974, 33, 19.

5 Lefrak, E A, et al, Cancer, 1973, 32, 302.

${ }^{6}$ Praga, C, et al, Adriamycin Review. Ghent, European Press Medikon, 1975.

7 Al-Ismail, S A D, Parry, D H, and Whittaker, J A, British Medical fournal, $1977,1,815$.

${ }^{8}$ Rinehart, J J, Lewis, R P, and Balcerzak, S D, Annals of Internal Medicine, $1974,81,475$.

9 Minow, R A, Benjamin, R S, and Gottlieb, J A, Cancer Chemotherapy Reports, 1975, 6, 195.

10 Weiss, A J, and Manthel, R W, Cancer, 1977, 40, 2046.

11 Weissler, A M, Harris, W S, and Schoenfeld, C D, American fournal of Cardiology, 1969, 23, 577.

12 Weissler, A M, Harris, W S, and Schoenfeld, C D, Circulation, 1968, 37, 149.

${ }^{13}$ Lewis, R P, et al, Circulation, 1977, 56, 146.

14 Garrard, C L, Weissler, A M, and Hodge, H T, Circulation, 1970, 42 , 455.

15 Al-Ismail, S A D, and Whittaker, J A, Lancet, 1978, 1, 1315.

16 Bonadonna, G, et al, in 8th International Congress on Chemotherapy, vol 3, ed G K Dalkos. Athens, Hellenic Society for Chemotherapy, 1973.

17 O'Bryan, R M, et al, Cancer, 1977, 39, 1940.

18 Bristow, M R, et al, Circulation, 1976, 53, suppl No 2, p 80

19 Mason, J W, XVII Congress of Internotional Society of Haematology, 1978, $1,230$.

${ }^{20}$ Jones, S E, Ewy, G A, and Groves, B H, Proceedings of the American Association for Cancer Research, 1975, 16, 228.

${ }^{21}$ McDonald, I G, and Hobson, E R, American Heart fournal, 1974, 88, 454.

${ }^{22}$ Lenaz, L, and Page, J A, Cancer Treatment Review, 1976, 3, 111.

${ }^{23}$ Arena, E, et al, Proceedings of the International Symposium on Adriamycin, ed S K Carter et al, p 96. New York, Springer Verlag, 1972.

\title{
Comparison of central nervous system malformations in spontaneous abortions in Northern Ireland and south-east England
}

\author{
J C R M MACHENRY， N C NEVIN，J D MERRETT
}

British Medical Fournal, 1979, 1, 1395-1397

\section{Summary and conclusions}

A study of 1140 pregnancies ending in spontaneous abortion disclosed a central nervous system (CNS) malformation in $4.9 \%$ of all complete conceptuses. Life-table analysis suggested that the incidence of CNS malformations is $16 / 1000$ at the beginning of the eighth week of gestation. It was also estimated that only onefifth of these infants are born alive, $41 \%$ being aborted spontaneously and $38 \%$ stillborn.

A hypothesis that differences in the incidence of CNS malformations result from area differences in the mortality rate of malformed embryos and fetuses was examined by comparing the findings in Northern Ireland, an area of high incidence, with those in south-east England, an area of low incidence. In Northern Ireland 4.6\% of complete conceptuses had a CNS malformation compared with $3.0 \%$ in south-east England, but the difference was not statistically significant.

The Queen's University of Belfast, Belfast BT12 6BJ

J C R M MACHENRY, MB, MRCOG, research fellow in medical genetics (present address: Craigavon Area Hospital, Craigavon, Northern Ireland) N C NEVIN, MD, FRCP, professer of medical genetics

J D MERRETT, BSC, PHD, reader in medical statistics
There is no evidence that in Northern Ireland a lower mortality rate among malformed fetuses and embryos is responsible for the high incidence of malformation at birth. The geographical variation of CNS malformations in the United Kingdom still awaits explanation.

\section{Introduction}

In the United Kingdom the incidence of central nervous system (CNS) malformations shows a pronounced geographical gradient, which steadily increases from the south and east to the north and west; the incidence (per 1000 total births) in southeast England is $2 \cdot 95,{ }^{1}$ in Wales $7 \cdot 6,{ }^{2}$ and in Northern Ireland $8 \cdot 6 .^{3}$ This gradient has been confirmed by several other reliable studies. The ratio of the prevalence of spina bifida to anencephaly is relatively constant, with a slight excess of spina bifida. In a study of regional variation in incidence of these malformations at birth, Roberts and Lloyd ${ }^{4}$ found an inverse relation between previous spontaneous abortion rates and the prevalence at birth of CNS malformations. They hypothesised that there is little or no difference in the incidence of CNS defects shortly after conception and that the observed differences in the third trimester arise only because of a greater prenatal mortality rate among malformed embryos in areas of low incidence. This may be tested by examining spontaneously aborted fetuses from areas with high and low incidences of CNS malformations; if correct there should be a higher proportion of aborted conceptuses with CNS defects in the area of low incidence. ${ }^{5}$ In south-east England 